\title{
Leisure and Quality of Life among Parents of Children with Autism Spectrum Disorder - A Review Based Analysis
}

\author{
Menezes Ida Sylvia*, \& D'Mello Laveena** \\ *Research Scholar, College of Social Sciences and Humanities, Srinivas University, \\ Mangalore, India. \\ Orcid ID: 0000-0001-7654-9217; Email: dishaasd2006@gmail.com, \\ ** Associate Professor, School of Social Sciences \& Humanities, Srinivas University, \\ Mangalore, Karnataka, India. \\ Orcid ID: 0000-003-1935002X; Email: lavynoronha@gmail.com
}

Area/Section: Psychology.

Type of the Paper: Review Based Analysis.

Type of Review: Peer Reviewed as per $|\mathrm{C}| \mathrm{O}|\mathrm{P}| \mathrm{E} \mid$ guidance.

Indexed in: OpenAIRE.

DOI: https://doi.org/10.5281/zenodo.4903314

Google Scholar Citation: IJMTS

\section{How to Cite this Paper:}

Menezes Ida Sylvia, \& D’Mello, Laveena, (2021). Leisure and Quality of Life among Parents of Children with Autism Spectrum Disorder - A Review Based Analysis. International Journal of Management, Technology, and Social Sciences (IJMTS), 6(1), 176188. DOI: https://doi.org/10.5281/zenodo.4903314.

International Journal of Management, Technology, and Social Sciences (IJMTS)

A Refereed International Journal of Srinivas University, India.

CrossRef DOI: https://doi.org/10.47992/IJMTS.2581.6012.0139

(C) With Author.

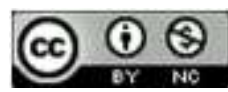

This work is licensed under a Creative Commons Attribution-Non-Commercial 4.0 International License subject to proper citation to the publication source of the work.

Disclaimer: The scholarly papers as reviewed and published by the Srinivas Publications (S.P.), India are the views and opinions of their respective authors and are not the views or opinions of the SP. The SP disclaims of any harm or loss caused due to the published content to any party. 


\title{
Leisure and Quality of Life among Parents of Children with Autism Spectrum Disorder - A Review Based Analysis
}

\author{
Menezes Ida Sylvia*, \& D'Mello Laveena** \\ *Research Scholar, College of Social Sciences and Humanities, Srinivas University, \\ Mangalore, India \\ Orcid ID: 0000-0001-7654-9217; Email: dishaasd2006@ gmail.com, \\ ** Associate Professor, School of Social Sciences \& Humanities, Srinivas University, \\ Mangalore, Karnataka, India. \\ Orcid ID: 0000-003-1935002X; Email: lavynoronha@gmail.com
}

\begin{abstract}
Purpose: Owing to the time-consuming job of caring for their child's family and friends, parents of children with autism spectrum disorder risk losing family relationships. The main aim was to identify and intervene in the quality of life of parents, the interventions offered to parents as primary caregivers of children with ASD. To explore parents' perspectives on beneficent for children with autism in connection with formative years, resources, and to confront the consequences of upraising a child with ASD.
\end{abstract}

Design/Methodology/Approach: Systematic literature, resulting in the publication of 27 studies that focused on the living standards of parents of children with ASD. Systematic literature scrutiny was performed using the search words "autism spectrum disorder," "primary caregiver/ parents/ mother" and "Quality of life" in the electronic databases Research gate, Academia, Google Scholar, and PsycInfo.

Findings/Result: QOL autism-specific assessment tools were limited and hence, most studies have employed a general measure tool to assess the influence of the diagnosed disorder on the physical and psychological well-being of parents/caregivers.

Originality/Value: The sequel of this study advocate that to date, the appraisal of quality life in parents of children with ASD into clinical practice has been rationalized by the shortage of autism-specific scales. As generically do not catch all pertinent aspects of living with ASD raising the need for immediate measures. Implementing parental interventions in parallel with the child's interventions may raise QOL.

Paper Type: Systematic literature review-based analysis.

Keywords: Autism Spectrum Disorder, Parents, Autism Spectrum measures, Quality of Life

\section{INTRODUCTION :}

Autism is a distinct mental disorder characterized by deficient relationships between people with communication difficulties. There will be repetitive behaviors and restricted interests. Some with autism spectrum disorder (ASD) remain nonverbal with significantly associated disorders whereas others are autonomous and possess extraordinary intelligence [1]. The duration and process of caregiving to a child with autism are extremely demanding and strenuous. It demands a greater sacrifice on behalf of the mother and they may constantly have to face sadness, disappointment, anger, depression, and other complex emotions. They also reported that they experience physical illness associated with sciatica, carpal tunnel syndrome, migraine, and other psychogenic disorders particularly apply to the mothers provide physical assistance also to autistic children. In addition to the impact on physical wellbeing, the mothers also suffer from adverse emotional extremes. depression and sadness are the most commonly reported disorders as a result of pessimism about the rate of progress made by the child. In elaborating the persistent emotional suffering of mothers, this is often categorized as chronic sorrow. The term 'leisure' is defined and elaborated by many renowned psychologists and in essence, they all come to similar agreements. Leisure is often defined as the subjective level of experience of caregivers of free time away from the dependent. Again, free time can be categorized 
manifold to include work domestic chores, professional training, personal care, etc. Each caregiver has a varied idea of leisure and it's again dependent on geographical, time, and supporting infrastructure in fulfilling goals of such desires. It could be described as simply passing time, escapism from reality, or just remaining lethargic by withdrawing oneself from all external pressures and duty compulsions. Leisure is considered and explained as free time [2]. Leisure is reliant on the people, situation, and need and is experienced differently by everyone. Given these observations, we come to understand that it is important for any human to indulge in leisure activities regardless of other engagements. Therefore, particularly in the case of mentally/ physically stressed individuals due to various perceived constraints, involving in leisure activities to maintain a balanced and focused outlook in life. Leisure time is commonly considered as activities that provide relaxation and make the caregivers/mothers recharge from the day-to-day burden of caregiving. It is also a means to restore energy when they feel exhausted. Leisure activities promote a sense of well-being which is an important aspect of rejuvenating. There are different types of leisure activities which include active (physical activities) and mentally stimulating. The researchers have shown that active leisure activities have been more beneficial than mentally stimulating ones.

People have many dreams for their children. Verbalization of these expectations does not occur, but deep down they remain. When the diagnosis of autism is given, their images of their child's potentials vaporize. They start imagining that the hopes they once visioned will be impossible [3]. Autism affecting family life is a question an individual wonder! That is a valid point of concern. It is effortful for parents to process the news that their ward has autism, and they begin to understand that their lives are bound to be entirely different than what they had anticipated it to be and the news is overwhelming. When there is a child on the spectrum social activities become a bother. Easy accommodation is not easy for autistic children. The family will have expectations and try to fulfill them as realistic as possible but it will not turn as realistic as they had seemed it to be. Despite situational adjustments memories cannot be made. Though families dream to involve together, they often do not indulge in activities because they appear too difficult to manage. Facets of family life that affected by the diagnosis of autism are family recreation, finances, parents' physical and mental wellbeing, meeting siblings' needs, sibling relationships, marital relationships, housekeeping, relationships with friends, neighbors, and relatives. Having a child with autism presents a number of problems that can have a direct negative effect on parents and family functioning. The impacts on various aspects of family lives are affected including general household chores, expenditure, minimized recreation and leisure activities, significant stress throughout all family members, physical health of family members, ignorance or neglect of other children's needs, strained sibling relationships. There will be unstable relationships with extended family, friends, and neighbors. The social and communication deficits affect total family members as they will not be part of any such gatherings [4]. The routine with a special need with distinctive challenges, will not be able to cope even after they pull themselves over the early dismay. A wide range of feelings is likely to be felt. It is heartbreaking to witness something that you wish so much, a desire so much, and yet not acquire it. The heightened desire to succeed will make you "revisit" the grief concomitantly and intermittently putting aside their own desires and feelings. Due to the diagnosis changes occur not only in the life of the child diagnosed but also in that of family members. Families and relationships may be strengthened by coping with the pressures of having an autistic child, through a great support system and a lot of hard work to avoid tragedy. Having an autistic child is stressful and time-consuming. This often conflicts with the need and desire to spend time with other family members neglecting their own needs and self-care.

\section{OBJRCTIVES :}

The objectives of this review paper are:

(1) Review of literature on intervention of Parents of Children with Autism Spectrum Disorder.

(2) Identifying research gap on Leisure and Quality of Life among Parents of Children with Autism Spectrum Disorder based on literature review.

(3) Identifying various research agendas related to Leisure and Quality of Life among Parents of Children with Autism Spectrum Disorder using focus group method.

\section{MATERIAL AND METHOD :}


A systematic literature review was performed using the search words "autism spectrum disorder," "primary caregiver/parents/mother" and "leisure time and leisure activities" in the electronic databases Research gate, Academia, Google Scholar, and PsycInfo. The year of publication was not limited. Unmatched research, looking at QOL in people with other disabilities, was omitted from the list. After that, the abstracts of the required papers were screened for relevance. It's worth noting that ASD, as described in the DSM-5, involves children diagnosed with "Autistic Disorder," "Asperger's Disorder," and "Pervasive Developmental Disorder," as defined in previous imprints of the DSM. All applicable studies were included resulting in the publication of 27 studies.

\section{RELATED WORK BASED ANALYSIS :}

Nancy Grace et al (2021) [5], used a non-experimental descriptive cross-sectional research design and a quantitative research method 120 samples India Lucknow city. The WHOQoL-BREF was accustomed to measure caregivers' QOL [6]. When the data was analyzed, it was discovered that $59.1 \%$ had low standard QOL in the psychological domain and 56.6 percent had poor QOL in the physical domain. In the psychological and environmental realms, the caregiver's QOL differed significantly depending on the period of child care. Under the environmental domain, zero substantial contrast in caregivers' QOL regarding age. The research has identified a need for long-term, need-based approaches that could enhance caregivers' QOL.

Jain, A., et al. (2019). [7] A cross-sectional sample of 90 caregivers for autism was performed in Lucknow's child and adolescent psychiatry outpatient departments. Since services were more readily available, caregivers who knew about the child's problem, "Autism," and how to handle it had substantially improved environmental health than those who did not. The extent of disability among autistic children did not make a difference in the life of caregivers. According to the author, social, cultural, and economic factors all played a role in their ability to obtain an adequate diagnosis, care, and intervention. Many households are unable to access the limited resources and services available due to their socioeconomic status. The indirect impact of the spending and the nonworking parents creates a significant problem for the economy of the country.

Katherine M. Walton (2019) [8], her research looked into the correlation between family leisure participation, leisure satisfaction, family functioning, and family life satisfaction. Participants of ASD $(n=112)$ and parents of children with normal development $(n=123)$ from Ohio participated in the study. According to the reports, parents of children with ASD reported the same extent of leisure activity as parents of normally developing children. They did, however, find that leisure time was associated with poor family contact and lower satisfaction with family life. Several researchers have also investigated the implementation and balancing of family leisure activities that lead to family communication as well as leisure and family interaction. Katherine, in her study, found that leisure satisfaction was an important indicator than involvement of leisure. The acceptance of leisure devotion as a valid criterion for leisure enjoyment. They assessed that family leisure engagement was connected to family complacency mediated by family functioning. In contrast to families without ASD or other disabilities, families with children with ASD engaged in less family recreational pursuits and had less satisfying leisure. The report, however, did not look at leisure satisfaction or family life satisfaction. Due to increased depression in this population and the study that leisure fulfillment improves mental wellbeing, neither of these studies considered how caregivers' psychological condition could undermine this view.

SooHoo A. A (2019) [9] Diagnose postponement, trouble dealing with ASD problem behaviors, and fewer social platforms and recreational occasions were all linked to elevated stress levels in caregivers of people with ASD. According to the report, caregiver stress, caregiver self-efficacy, caregiver social network, and family quality of life were all determinants of well-being both physically and mentally. The quantitative research discovered that caregiver self-efficacy and social networks, as well as social networks and quality of life, have beneficial associations. Stress was found to have a negative relationship with family quality of life, social network, and self-efficacy; as a result, the more stress caregivers reported, the lower their quality of life, social network, and self-efficacy. 
Yorke Isabel et al (2018) [10]in their meta-analysis studied affected Children with the diagnosis of ASD and Psychological affliction in Parents, 61 studies correlated with EBP and factors that cause psychological damage in parents. The study was aimed to establish associations among EBP and factors that cause affliction, mental health problems, and stress in families. The associations of child facets (ASD grade; intelligence), parent facets (coping strategy; parenting styles; social support), and contextual facets (family income; socio-economic status) were statistically accounted for.

Márcia Cristina Maciel de Aguiar (2018) [11] in Brazil, a qualitative study was performed utilizing a narrative approach and semi-structured interviews. In addition to a mother's emotional distress from caring, the additional responsibility of household tasks should be managed. According to a systematic study, parenting necessitates reorganizing family structures, which repeatedly causes inner and outer exhaustion, especially for mothers. Parents account for increased health risk comparing with normal parents and research finding that this is more prevalent in mothers than in fathers. To deal with their child's demands, mothers had to prohibit free-time and professional interests, dropping engagements. The majority of the mothers expressed dissatisfaction with their husband's ability to assist them with daily activities and the child's demanding care. A decrease in intimacy as well as the difficulty in procuring privacy leading to disconnection (72 percent). Tensions, and conjugal disputes as a consequence of inability to attend a variety of family functions. Because of social injustice and shame, mothers stopped taking their children out. As a result, they appeared to separate themselves, resulting in shifts in mothers. Parents broke off those social interactions because they were dissatisfied with others judging their children's actions.

Ereny Gobrial (2018) [12], in Egypt, focused on the experiences, concerning formative years, resources, and the implications of raising a child with ASD. The researcher took a qualitative approach and used grounded theory to interpret the data using thematic content analysis. Mothers acquiring information could enhance understanding and minimizing the repercussions from the diagnosis. The mothers in this study were dissatisfied with their family life. In contrast to high-income countries, little research has been conducted on the encounters of upraising a child from poor to middle-class families and nonWestern nations. Acceptance, positive attitude, character development, faith, parent support networks, and fostered wellness were among the coping mechanisms examined by the author in her research. The findings offered important insight into the lives of mothers, exposing what it's like to be a mother in a low-medium-income country caring for a similar child. Such mothers endured a negative effect on their social lives, mental well-being, and sacrifices as a result of their children's ASD. Understanding mothers' encounters while upraising these children is critical in supplying care. Improving programs desperately needed in Egypt, both domestically and globally, to provide policy and legislative processes. The findings emphasized the value of implementing family-centered programs that improve skills, assist in dealing with upsetting feelings and challenges, and can be used to improve and provide services to children with ASD.

Bateman J. K. (2017) [13] looked at how a parent coaching kit based on Positive Behavior Strategy and adult learning theory improved the quality of life for families of ASD children at a young age. Efficient parent coaching activities may elevate schedules developed during early intervention, according to the results of this report. This intervention resulted in many positive results, including increased parent awareness and trust in implementing intervention at home, increased fidelity of target ability implementation, decreased child involvement in demanding behavior at home, and parents' credence. Furthermore, the findings contribute to an improved belief towards intervention strategies for their children. Overall, the safe delivery of well-organized parent care kits allows parents to gain knowledge and adopt interventions, giving beneficial results for both parents and children in a variety of behaviors.

Pisula E., Porębowicz-Do“rsmann A., (2017) [14]. One of the most critical resources for parental change would be family functioning. Parenting between different genders experiences an imbalance in family system characteristics. Functioning of the family with parents of special needs was lower than normal parents. Parental stress was substantially greater in special needs parents than in normal parents. 
Vasilopoulou, E., Nisbet, J. (2015) [15] examined parental, child-related, and contextual facets that form QoL from qualified studies. Emphasizing the importance of designing interventions to affect strategies and capital in the future. Extraction of data of participants' exhibit detrimental impact on the difficulty of raising. Physical QoL was more consistently influenced, and many children, parents, and environmental characteristics influenced parental QoL.

The Godin-Shepherd Leisure Time Questionnaire was used to examine the daily active exercises of participants of both genders between 6 to14 years (GLTEQ). There is a substantial gap consistent with ASD and general population research. A less rate of active involvement linked to sociodemographic factors according to the study of Memari et al. (2015) [16].

Garret J.R. (2014), [17] aimed to see parents coping with adversity when raising their child with severe developmental needs and difficulties. 153 parents to see how caregivers handle adversity when raising significant developmental delays and difficulties, showing recovery. Adaptations, locus of influence, sense of soundness, ambiguity, intensity, and urges are all considered in this analysis. Lower perceived stress was linked to improved FQOL, according to the findings. Higher FQOL was linked with elevated scores on illness uncertainty. As a mediator between ambiguity and FQOL, a sense of coherence was found to have a partial mediation. The relationship between uncertainty and FQOL was not mediated by locus of influence.

Valsamma, E., Rudi, H., Amelia, W., and Kwok, P. (2014) [18] visualized the need for ASD-specific Quality of Life indicators, as the available scale does not cover the necessary items. An evaluation method was invented. A clinical and research-ready questionnaire for guardians in two categories, one for parents' assessment on child's disruptive behaviors and the other on personal health with eight-core QoL domains proposed in this model. The study had outstanding self-consistency, strong knowngroups validity, and good convergent validity between the two groups. Implementing parental interventions in parallel with child's interventions may raise QOL. A low level of QoL and mental health aided the evaluation of the QoLA's convergent validity. When compared to nonclinical normative evidence, the findings revealed the psychosocial challenges faced by guardians. In the current research, mothers had elevated levels of depression, anxiety, stress and had higher efficacy ratings, implying that they were more secure in their ability to deal with difficult situations as parents. Parental psychological traits as low perceived efficacy, external control, and emotions with coping styles are associated with low discerned social support.

Melton K., K. (2014), [19] 884 households in the United Kingdom (UK) were surveyed online using FLAP (Family Leisure Activity Profile) and FACES II. The results of this study back up previous research that shows a correlation linking family leisure participation and aspects of family functioning proposed in the Core and Balance Model. Furthermore, the three main contributions of this study will be highlighted: an inter-rater agreement in family leisure indicators, new measures of family recreation locations using the FLAP index, and the degree of scales for family leisure. A new addition to the FLAP index was the conceptual advancement of core and balance family leisure habits to reflect arousal affordances of recreation environments. Centered on the incongruity affordances of recreation settings, this study offered a new conceptualization of core and balance leisure trends. Second, this study proposed new forms of reliability estimates and inter-rater agreement data not previously available in published literature relevant to the FLAP index.

Perumal V. et al (2014) [20] aimed to connect the QOL of caretakers of autism, physically disabled to the control group with the level of autism severity. Children's disabilities not only impose a financial hardship on their families, but they also contribute to an inadequate state of the physical, psychological, and social factors. When connected to all these three groups Autism Spectrum Disorder have a less high quality of life. The results suggest explaining the reason, listening to the parent's concern, involving parents in the treatment protocols, educating and supporting the parents throughout the process of diagnosis and management is equally important along with the professional's work on symptomatic management. Conformity and value system causes a heavy impact stressing the need for broader 
intervention goals, to develop supportive programs highlighting the need to create government policies to support the parents.

Norah Louise Johnson (2009), [21] 387 parents completed web-based surveys using a cross-sectional design. Obscurity and social forums were causal precursors of stress linked to the diagnosis, care choices, and prognosis for children with ASD, according to the Transactional model. Stress is believed to be mediated by social networks that have a positive effect on parental wellbeing.

Agate R.J (2009), [22] Leisure satisfaction was measured using Family Life Scale gauging how happy people were with their families, taking leisure as a preceding element. A total of 898 families revealed a correlation between variables used. Samples from across the United States were included in the study. The findings all family leisure and family life satisfaction. Elemental leisure satisfaction was most associated with satisfaction with the different age groups of the family members in each developmental stage domain. Within families, paired data from different developmental stages offered fascinating insights into the essence of the partnership.

Zabriskie \& Mc Cormick (2003), [23] The goal of this study was to see a correlation linked to leisure engagement and life satisfaction. Data was analyzed at three levels: parent, child, and family. From the perspective of the parents, leisure engagement as kinship was the best multicomponent of family happiness than from the children's standpoint. As kinship, only the strata comprising the Elemental and Balance family leisure elements explained a notable portion of the components in family satisfaction. The three scales included in the research questionnaire produced three sets of data provoking responses from the parents, youth responses, and the individual mean scores. Taking part in leisure and life satisfaction intertwined, especially from the viewpoint of parents and families. If family satisfaction is a central predictor of a harmonious life, participation is the most important facet leading to a superior level of family life, according to the parents and families in this study. Mean family-centered and balance leisure habits were positively correlated with mean family satisfaction.

\section{DISCUSSION :}

Efforts were made to understand the importance of leisure in day-to-day life of mothers of children with ASD to typical mothers or with reference data. Which aspects of QoL are the most impacted there by the factors that influence parental QoL? The efforts were laid to understand the role of leisure that affects the QoL of parents/ primary caregivers. The reviews on various literature could not throw much light on the objectives as mentioned above either on the Leisure activities of mothers or its impact due to the diagnosis on the quality of life due to the demands on mothers with the diagnosis of autism in the family. Very few relevant studies were studied on the QoL of mothers as a whole globally. The role of mothers with autism children is less studied and relevant aspects that affect their QoL and social functioning in the Indian context are least understood. Very valuable information throughout the review is that there is no specific leisure time assessment tool or leisure activities assessment tool relevant to the Indian context. Leisure participation or satisfaction scales are generally focused on the disordered child's welfare and or the typically developing children's and or the families. Leisure participation, family functioning, family life satisfaction was studied by few researchers. The finding shows that parents had the same level of leisure activity in comparison with the normally developing population. Leisure time was associated with poor family contact, lower satisfaction with family life. Leisure satisfaction was an important indicator of involvement of leisure as studied by Katherine M. Walton [8]. Leisure engagement is the mediator for both family functioning and family life satisfaction. The encounter with identification, misdiagnosis, insufficient understanding, and parental prior experience endured a negative effect (stress) and dissatisfaction with family life in mothers. Early interventions, health care, financial burden, and stigma had a direct impact on their social lives, mental well-being, and sacrifices as a result of their children's ASD as reported by Ereny Gobrial [12]. Autism's severity and its related developmental problems have a detrimental effect on parents' ability to sustain assistance networks and difficulty in taking part in social assignations or family engagements with similar children affected with the disorder. On the other hand, the picture of refrigerator mother, with an added tag of depressive illness, with irresponsible behavior, negligence and ineffective maternal roles 
which led to increased stress both in the mother and the family thereafter, with physical ailments has been highlighted in the studies.

The limitation in these studies was, visualizing the need for QoL indicators in Autism Spectrum Disorders, QoL- A (Autism Specific Measure) to measure personal growth, self-determination, social inclusions, soundness of emotional health, physical and material robustness. Vasilopoulou and Nisbet [15] conducted a systematic analysis and discovered a negative association in one domain of the WHOQOL questionnaire in total nine studies conducted amongst ASD and typical parents. In four of nine studies, the caregivers affected the physical, psychological, and environmental realms. Much research has been performed to estimate the quality of life judging the parents' comfort while caring the children with special needs. However, lacking in the literature on QOL of mothers of autism and or autism spectrum disorder in India did not support much in identifying the components amidst affected. Literature on assessing the QOL of primary caregivers in Tamil Nadu, south of India evaluated the effect of ASD, their concerns about the detrimental future, and organize need-based assistance for the people giving primary care to this population. In Northern India Lucknow city in the psychological and environmental realms, the caregiver's QOL differed significantly depending on the period of child care. Under the environmental realm, age had no substantial difference. Caring for children with ASD has a multifaceted effect on caregivers' quality of life, necessitating the generation of long-term approaches to improve caregivers' QOL. The results will assist Indian policymakers in providing more and more targeted assistance to children with ASD and their caregivers.

\section{LIMITATIONS :}

There are a few flaws in the studies listed above. In addition to small sample size, the majority of studies employed parents seeking services in clinics and preschools as convenience sampling, resulting in bias. It's likely that the association between QOL and raising an ASD child varies in families who aren't connected to health, educational services, or support system. Future research that hires from the population will be able to resolve these drawbacks. In terms of perspectives, future research should involve a wider range of participants. To allow a more diversified sample or data obtained from various social groups and participants from different institutions should be included. Another drawback is the wide range of instruments used in these studies to determine QOL. None of these tests were designed specifically for people with ASD. As parents face particular difficulties in course of therapy, treatment, and daily schedules, QOL indicators specific to this group of participants' such as the QOLA, should be used in assessing QOL. The lack of longitudinal research adds to the limitations. Cross-sectional studies used to connect unidirectional causative relationships is a limitation. To gain insight, the effect of a child's autistic-related characteristics and associated parents' QOL, further longitudinal studies are required. Parenting itself is a challenge in the case of autistic child that requires more consideration from healthcare professionals, particularly those who work in the mental health field. For more efficient care of autistic children, care plans must be integrated for the betterment of parents in addition to the child's care. Healthcare professionals bearing in mind the parent's need, need to procure as well as the significant contribution that social and professional support may make in helping to cope with demands.

\section{RESEARCH GAP :}

More research is required to explore the connection between leisure involvement and leisure satisfaction, as only participation in leisure does not result in satisfaction. Family functioning in relation to leisure and psychological wellbeing of parents in families with autism, the challenges encountered in their attempts to engage in any leisure activities need to be explored. Parental psychological traits inefficient self-efficacy, insecurity, and negative emotional responses are associated with, diminished social support which recommends the involvement of social interaction. Social interaction through leisure doubles the benefit of the psychological wellbeing of the mother and the (feeling) of social support, which was low in the parents as per the study. Lower QoL in ASD parents in comparison with typically developing population emphasizes the importance of designing interventions to affect, healthcare, policy-making, funding decisions in future, to raise the Physical Component of QoL of parents that more consistently influenced by parent, child, contextual factors. Depression and mental well-being balancing through leisure is the need to study. Leisure time and leisure satisfaction, in Autism families and the challenges encountered by these families in pursuing leisure is the need of the hour. The findings 
emphasized the value of implementing family-centered programs that improve skills in dealing with distressing feelings and challenges, and they can be used to improve and provide services. Neither ASD severity nor maladaptive behaviors of an affected child that affect QOL, it is poor coping, isolation, social malfunctioning as elements of parental distress that affect QOL, which needs to be further studied and correlated. At future point, research may be conducted to determine the impact of different factors including the child's age, sibling status, the length of time after the diagnosis, and the number of availabilities of rehabilitation services. Determining the efficacy of various social support services and their benefit on their quality-of-life perceptions.

\section{POSSIBLE RESEARCH AGENDAS BASED ON RESEARCH GAP :}

This study presents a scoping review of evidence relating to knowledge, exposure and experiences of leisure time of mothers of children with autism. Autism is the developmental disorder diagnosed at the very beginning years of the family formation based on the focus group interaction. The initial diagnosis and the acceptance of the diagnosis itself is so unpleasant as the child they were anticipating is not the child they received. The family relationships impact due to this new transformation, as feelings of fear and worry encompass the family system. Fear of stigma shown by immediate family, social friends, society plays an important role for maternal stress. Mother of children with autism faces loss of the relationships between family members due to the time consuming, task of caring for their child family and friends. As more time is spent with the child, mothers face more challenges than fathers. Demanding care of the child deprives mothers time for socialization and leisure activities. This links up to cause the mother's loneliness, lack of social support and depressive symptoms. The fathers of autism children most of the time suppressing and not expressing their feelings and defenses as anger. In addition, it becomes sole responsibility of mother to take care of the autism child as single parent and fathers walk away without any guilt or responsibility.

Identifying the research gap, in the connection between leisure involvement and leisure satisfaction, I would like to adventure more on the possibility of involving leisure in day today life of mothers and primary care givers of children with autism. Throughout the review it is clear that no much importance laid on the significance of leisure in the life of care givers. Leisure satisfaction was an important indicator than involvement of leisure. The acceptance of leisure devotion as a valid criterion for leisure enjoyment. Family leisure engagement is connected to family complacency mediated by family functioning. No effort has been made to understand through leisure how one can uplift the psychological wellbeing of primary care givers. Stress was found to have a negative relationship with family quality of life, social network, and self-efficacy; as a result, the more stress caregivers reported, the lower their quality of life, social network, and self-efficacy. Rather its of great importance to see that certain amount of leisure introduced as a schedule in the life of caregivers along with the schedules of the child care. A decrease in intimacy as well as the difficulty in procuring privacy leading to disconnection. Sibling rivalry/ jealousy highlighted as impact of the diagnosis of autism or ASD. Family counselling and family therapies intermittently need to be installed as part of the child intervention. Coping mechanisms into the lives of low-medium-income mothers, caring for a similar child enduring a negative effect on their social lives, mental well-being, and sacrifices as a result of their children's ASD. Understanding mothers' encounters while upraising these children is critical in supplying care. Implementing family-centered programs that improve skills and improving programs to provide policy and legislative processes. Safe delivery of well-organized parent care kits allows parents to gain knowledge and adopt interventions, giving beneficial results for both parents and children in a variety of behaviors. Parenting between different genders experiences an imbalance in family system characteristics highlighting the need for psycho education of parents. Examining the daily active exercises of participants of ASD, a high rate of active involvement of caregivers need to be studied along with sociodemographic links. Study identified the need for ASD-specific Quality of Life indicators, a clinical and research-ready questionnaire as an evaluation tool for guardians as the available scale does not cover the necessary items which need to be successively carried further. Further search will be made to see if any type of mental health care recommended in a caregiver's life to balance the stress owing to the long run care of the child. Why such studies have not been conducted? Or why the importance of leisure in the life of caregiver and the mother has not been planned or prioritized? Is it not needed or does she get it unwelcomingly? The question arises why the health care professionals 
are not necessitating that through the care of the child the mother as a primary care giver personal and social space need to be taken care off through leisure involvement to fulfill the social, emotional realms. Leisure plays a significant role in paving stimulation in all domains of health, for both the mother and primary caregiver. It is the prime factor in evaluating the elements of poor quality of life in people with autism. Through leisure, the caregiver can participate in social functioning and enrich the social domain. The major four domains of the QOL scale cannot be balanced in the absence of leisure activity. It is rather overwhelming that no proper inventory that could evaluate or guide the leisure participation for parents, primary caregivers, and particularly the mothers with high demands of chores round the clock with the fear and anxiety behind the diagnosis. Given the mental health implications of caregiving for mothers, having lower mental HRQOL the researcher analyzed that chronic care of a child with ASD has a substantial effect on QOL, which needs to be discussed in intervention approaches. Poor coping, isolation, social malfunctioning as elements of parental distress that affect QOL, which needs to be further studied and correlated. As Autism Spectrum Disorder is chronic without a complete cure any successful outcome assists in identifying the effectiveness of the services provided thus shall improve their family's quality QOL.As we analyze the research gap, assessing the leisure time activities to mothers as well as primary caregivers of autism children, at the very beginning of the diagnosis of the child while creating the therapy and treatment plan, for psychological and physical wellbeing of the mother.

\section{IDEAL SOLUTION \& PRESENT STATUS :}

Recommendations of the study stresses on the measures to be adopted to improve the leisure time, quality of leisure time and the range of activities that indicates the satisfaction with psychological benefits received from leisure engagement, followed by relaxation benefits, aesthetic benefits and educational benefits.

Educating the mothers regarding the need of leisure time in one's own and the families' welfare is the utmost priority.

- Counselling should be given at very first visit once the diagnosis of autism is confirmed and the very next step of intervention offered while preparing the mothers for future respite and the care.

- The environment should be mother friendly where the mother should feel relaxed and comfortable during her respite time as she is the primary caregiver.

- There should be various range of leisure activities as scheduled in the checklist for the best use of the mother depending on her need and preference.

- Mothers should be instructed properly about the active participation of leisure to be followed during the respite time offered.

- There should be more female trainers and coachers in the respite care to feel emotionally free and without any inhibitions in the participation.

- Periodic discussions and the benefits of leisure should be made aware to the mothers.

- The self-confidence of the mothers should be boosted and the guilt component if any should be removed by counselling and guidance.

- The other members of the family, the spouse and the grown-up children if any, should be very supportive towards the leisure time of the mother.

- Proper counselling should be given to the family as a whole towards the involvement of leisure time of mother, highlighting its utmost need for the physical and psychological welfare of the mother.

- Proper education should be given to make use of the leisure time, removing the guilt if any.

- The trainers should be co-operative and the atmosphere of the amenity should be friendly to accommodate the emotional feelings of the mothers who have received the diagnosis of autism.

- Periodic counselling should be given to mothers and make them aware of the importance of leisure and the empowerment of women.

- Education regarding the role of leisure on the physical growth and psychological rejuvenation must be implemented.

\subsection{Most suitable Intervention based solution:}


The ideal solution will be to implement one hour intervention-based relaxation therapy in suitable milieu for the primary caregivers especially the mothers, parallelly with their wards therapy sessions. This will benefit in more suitable way as the child will be under the care of specialist and the mother will not be suffering from fear and anxiety or the guilt of not offering demanding care to the special need. A well framed need-based program can be carried out as treatment modality towards the wellness of the mother (primary caregiver) according to the intervention schedules offered to the disordered child. This can be made available in all clinical services or centres, offering the therapeutic care for the child. The pre-test and post-test evaluation through stimulus questionnaire will be evaluated and analysed for a period of six months. This will provide a better uplift towards the physical, psychological and emotional domains of the parent that was the drawback of majority of studies reviewed.

\subsection{Most suitable Inventory based solution:}

The major four domains of the QOL scale cannot be balanced in the absence of leisure activity. It is rather overwhelming that no proper inventory that could evaluate or guide the leisure participation for parents, primary caregivers, and particularly the mothers with high demands of chores round the clock with the fear and anxiety behind the diagnosis. A checklist for leisure activities of mother with autism child for Indian context need to be prepared. The questionnaire should consist the stimulus questions in section A, to evaluate the pre test requirement of the intervention proposed and also the posttest outcome to analyze. Under section B there should be a list of leisure activities more commonly used by Indian women under categories to ease the statistical analysis. Such inventory or checklist will be prepared and standardized.

\section{CONCLUSION :}

This study was conducted to look into the relationship between mothers of autistic children's leisure activities and their contribution to their physical and mental well-being. We need to consider the principles of autism, the physical and mental strain of mothers, and their relationship with leisure activities before we can begin this research. This may be nothing more than recreational sports, which are diversionary activities. Researchers have made an attempt to comprehend the advantages of physically active leisure activities over mentally relaxing ones. There has been a rise in stress levels as a result of insufficient knowledge and disorganized preparation strategies for caring for autistic kids. The research's aim and reasoning have been explained in order to gain a better understanding of how parents/caregivers of children with autism perceive their free time and how they use it when given a break from their parental responsibilities. Slow psychological transformations of parents especially mothers and caregivers of autistic children due to prolonged exposure to the company of autistic children and the extent to which it affects have been raised. It is evident from studies from all over the world that caring for an autistic child has a huge effect on the parent's or caregiver's quality of life. Due to the mental, physical, sometimes social, and often financial pressures of taking care of a disabled child, parental QOL is likely to be less high than that with parents of normally growing children. The elemental characteristics of ASD, such as communication inability and disruptive behaviors, as well as genetic or environmental factors, can trigger greater parental distress, resulting in lower QOL. As a result, it's important to enroll, a family-centered approach, as well as schedules for QOL intervention for parents in conjunction with child care, is essential. In consultation with experts in the field, we have come to understand that no such studies have been conducted on this topic in India to date.

\section{REFERENCES :}

[1] American Psychiatric Association, (1994). Diagnostic and statistical manual of Mental disorders; $D S M-V$. Washington, D.C.: Author.

[2] Bedini, L., \& Bilbro, G. (1991). National recreation and park. Journal of Leisure research, 33(1), $32-55$.

[3] DeJong, P., \& Berg, K. (2008). Interviewing for solutions (3rd ed.). Belmont, CA: Brooks/Cole. evideo.

[4] Mays, N. M, Beal-Alvarez, J., \& Jolivette, K. (2011). Using movement-based sensory interventions to address self-stimulatory behaviours in students with autism. Teaching Exceptional Children, 43(6), 46-52. 
[5] Renford NG Robert, Arulappan J, Thomas KD Edward, Karuppiah KM, Chinnathambi K Thangaswamy GC. (2020). Quality of Life of Caregivers of Children with Autism Spectrum Disorder in Tamil Nadu, South India. Int J Nutr Pharmacol Neurol Dis., 10(1), 57-64.

[6] World Health Organization. WHOQOL-BREF: introduction, administration, scoring and generic version of the assessment: field trial version, December 1996. Geneva: World Health Organization 1996.

[7] Jain, A., Ahmed, N., Mahour, P., Agarwal, V., Shrivastav, N., K., Chandrakanta. (2019). Quality of life of caregivers of autistic children and adolescents visiting health facilities in Lucknow City, Uttar Pradesh, India: A cross-sectional study. Indian J Community Med, 44(1), 157-161.

[8] Walton, K., M., (2019). Leisure Time and Family Functioning in Families Living with Autism Spectrum Disorder; Autism., 23(6), 1384-1397.

[9] SooHoo, A., A., Respite and Well-being among Families with Children with Autism Spectrum Disorder; https://doi.org/10.7916/d8-jf16-cm37;oai:academiccommons.columbia.edu: 10.7916/ d8-jf16-cm37.

[10] Yorke, I., White, P., Weston A., Monica Rafla, M., Charman T., Emily Simonoff E. (2018). The Association Between Emotional and Behavioral Problems in Children with Autism Spectrum Disorder and Psychological Distress in Their Parents: A Systematic Review and Meta-analysis. Journal of Autism and Developmental Disorders, 48(1), 3393-3415.

[11] Maciel de Aguiar,M., C. \& Pereira Pondé, M., (2018). Parenting a child with autism. 23711_JPB, 68(1), indb 45.

[12] Ereny Gobrial (2018). The Lived Experiences of Mothers of Children with the Autism Spectrum Disorders in Egypt: Social Sciences, 7(8), 133, 1-11.

[13] Katherine, J., B., (2017). The Effects of the Implementation of Parent Coaching to Increase Quality of life for Children and Families Affected by Autism Spectrum Disorder. WReserach Work Archive; Dissertation/ Thesis/ Education seattle (619).

[14] Pisula E, Porębowicz-Do"rsmann A (2017). Family functioning, parenting stress and quality of life in mothers and fathers of Polish children with high functioning autism or Asperger syndrome. PLOS ONE, 12(10), e0186536.

[15] Vasilopoulou, E., Nisbet, J. (2015). The quality of life of parents of children with autism spectrum disorder. Research in Autism Spectrum Disorders, 23(2016) 36-49.

[16] Memari, A. H., Panahi, N., Ranjbar, E., Moshayedi, P., Shafiei, M., Kordi, R., \& Ziaee, V. (2015). Children with Autism Spectrum Disorder and Patterns of Participation in Daily Physical and Play Activities. Hindawi Publishing Corporation Neurology Research International. 2015(1), Article ID 531906, 1-7.

[17] Garrett, Jessica R., (2014). Factors Related to Quality of Life in Families of Children With Autism Spectrum Disorder. Wayne State University Dissertations. Paper 1092.

[18] Valsamma, E., Rudi, H., Amelia, W., and Kwok, P. (2014). Conceptualisation and Development of a Quality of Life Measure for Parents of Children with Autism Spectrum Disorder. Hindawi Publishing Corporation Autism Research and Treatment, Article ID 160783. http://dx.doi.org/10.1155/2014/160783

[19] Melton, Karen (2014). Advancing Measurement of Family Leisure. Doctoral dissertation, Texas A \& M University. Available electronically from https :/ /hdl.handle .net /1969 .1 /153570.

[20] Vaithi Perumal et al. (2014). Quality of life in families of children with autism spectrum disorder in India. Journal of Pharmacy Research, 8(6), 791-797.

[21] Johnson, Norah, L., (2009). Understanding Relationships in Health Related Quality of Life for Parents of Children with Autism Spectrum Disorder. Paper 6. http:/lepublications.marquette.edu/dissertations mu/6. 
[22] Agate, J., R. et al. (2009). Family Leisure Satisfaction and Satisfaction with Family Life. Journal of Leisure Research, 41(2), 205-223.

[23] Zabriskie, R. B., \& McCormick, B. P. (2003). Parent and child perspectives of family leisure involvement and satisfaction with family life. Journal of Leisure Research, 35(2), 163-189.

************* 